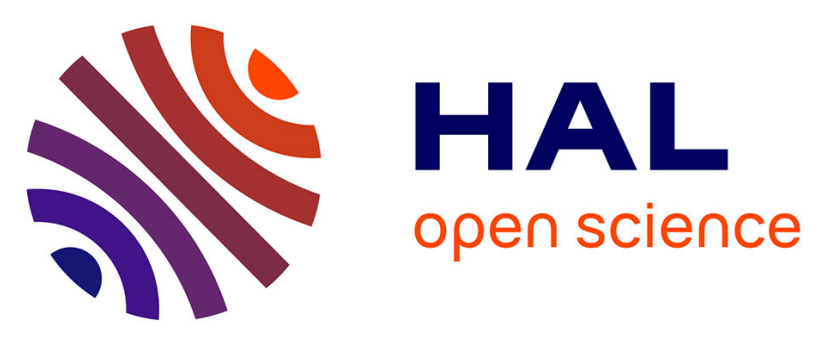

\title{
Comparison of high-temperature conversion and equilibration methods for the determination of d31-palmitic acid oxidation in man using continuous-flow isotope ratio mass spectrometry
}

Valérie Sauvinet, Laure Gabert, Maud Alligier, Sylvie Normand, Hubert Roth, Martine Laville, Michel Désage

\section{To cite this version:}

Valérie Sauvinet, Laure Gabert, Maud Alligier, Sylvie Normand, Hubert Roth, et al.. Comparison of high-temperature conversion and equilibration methods for the determination of d31-palmitic acid oxidation in man using continuous-flow isotope ratio mass spectrometry. Rapid Communications in Mass Spectrometry, 2011, 25 (19), pp.2749-2759. 10.1002/rcm.5173 . hal-03254888

\section{HAL Id: hal-03254888 \\ https://univ-lyon1.hal.science/hal-03254888}

Submitted on 9 Jun 2021

HAL is a multi-disciplinary open access archive for the deposit and dissemination of scientific research documents, whether they are published or not. The documents may come from teaching and research institutions in France or abroad, or from public or private research centers.
L'archive ouverte pluridisciplinaire HAL, est destinée au dépôt et à la diffusion de documents scientifiques de niveau recherche, publiés ou non, émanant des établissements d'enseignement et de recherche français ou étrangers, des laboratoires publics ou privés. 


\section{Comparison of High Temperature Conversion and Equilibration methods for the determination of $d_{31}$-palmitic acid oxidation in Man using Continuous Flow Isotope Ratio Mass Spectrometry}

\begin{tabular}{|c|c|}
\hline Journal: & Rapid Communications in Mass Spectrometry \\
\hline Manuscript ID: & RCM-11-0104.R1 \\
\hline Wiley - Manuscript type: & Special Issue Paper \\
\hline $\begin{array}{r}\text { Date Submitted by the } \\
\text { Author: }\end{array}$ & $\mathrm{n} / \mathrm{a}$ \\
\hline Complete List of Authors: & $\begin{array}{l}\text { Sauvinet, Valérie; Lyon University, CRNH Rhône-Alpes and Center } \\
\text { for European Nutrition, Safety and health; INSERM U1060, CarMeN } \\
\text { Laboratory } \\
\text { Gabert, Laure; Lyon University, CRNH Rhône-Alpes and Center for } \\
\text { European Nutrition, Safety and health; Hospices Civils de Lyon } \\
\text { Alligier, Maud; Lyon University, CRNH Rhône-Alpes and Center for } \\
\text { European Nutrition, Safety and health; INSERM U1060, CarMeN } \\
\text { Laboratory } \\
\text { Normand, Sylvie; Lyon University, CRNH Rhône-Alpes and Center } \\
\text { for European Nutrition, Safety and health } \\
\text { Roth, Hubert; Lyon University, CRNH Rhône-Alpes and Center for } \\
\text { European Nutrition, Safety and health } \\
\text { Laville, Martine; Lyon University, CRNH Rhône-Alpes and Center for } \\
\text { European Nutrition, Safety and health; INSERM U1060, CarMeN } \\
\text { Laboratory; Hospices Civils de Lyon } \\
\text { Désage, Michel; Lyon University, CRNH Rhône-Alpes and Center for } \\
\text { European Nutrition, Safety and health }\end{array}$ \\
\hline Keywords: & $\begin{array}{l}\text { deuterium, oxygen-18, continuous flow - isotope ratio mass } \\
\text { spectrometry, equilibration, high temperature conversion }\end{array}$ \\
\hline Abstract: & $\begin{array}{l}\text { During nutritional interventions, the ingestion of } d_{31} \text {-palmitic acid } \\
\text { and } \mathrm{H}_{2}{ }^{18} \mathrm{O} \text { allows assessment of dietary fatty acid oxidation from } \\
\text { cumulative }{ }^{2} \mathrm{H} \text { recovery in urine and estimation of the total body } \\
\text { water pool (TBW) from }{ }^{18} \mathrm{O} \text { dilution. Continuous flow }- \text { isotope ratio } \\
\text { mass spectrometry (CF-IRMS) coupled to either equilibration or } \\
\text { high temperature conversion techniques (HTC) permits }{ }^{2} \mathrm{H} \text { and }{ }^{18} \mathrm{O} \\
\text { enrichment measurements in biological fluids. Thus it was of great } \\
\text { interest to compare these methods applied to the determination of } \\
\text { dietary fatty acid oxidation. } \\
\text { Linearity, accuracy and correlation between CF-equilibration and } \\
\mathrm{CF}-\mathrm{HTC} \text { were first checked using }{ }^{2} \mathrm{H}-\text { and }{ }^{18} \mathrm{O}-\text { enriched water and } \\
\text { urine samples. Urine samples from } 14 \text { subjects were then measured } \\
\text { with both methods. }{ }^{2} \mathrm{H} \text { - and }{ }^{18} \mathrm{O}-\text { raw data were normalised against } \\
\text { calibration lines. The final aim was to study the impact of } \\
\text { normalised raw results on physiological data (i.e. TBW and } \mathrm{d}_{31^{-}}\end{array}$ \\
\hline
\end{tabular}


palmitate recovery).

No significant difference was observed between $\delta^{18} \mathrm{O} \%$ ond $\delta^{2} \mathrm{H} \%$ o enrichment measurements depending on the analytical method used. Volumes of TBW calculated from $\delta^{18} \mathrm{O} \%$ o enrichments measured either with CF-equilibration or CF-HTC were not significantly different with respectively $45.2 \pm 1.0 \mathrm{~L}$ or $45.7 \pm 1.0 \mathrm{~L}$ (mean \pm sem, $p=0.09$ ). Palmitic acid oxidation results obtained from $\delta^{2} \mathrm{H} \%$ o enrichment measurements and TBW from CF-equilibration vs CF-HTC were not significantly different $(p \geq 0.26)$ with respectively $16.2 \pm 1.6 \%$ vs $16.2 \pm 1.1 \%$ at $8 \mathrm{~h}, 18.7 \pm 2.0 \%$ vs $17.6 \pm 1.3 \%$ at $12 \mathrm{~h}$ and $21.7 \pm 1.9 \%$ vs $21.5 \pm 1.3 \%$ at 3 days postdose (mean \pm sem).

Thus, even if CF-HTC was preferred because it was more practical to carry out, both methods allow study of dietary lipid oxidation in man and generate similar results.

\section{SCHOLARONE" Manuscripts}


Comparison of High Temperature Conversion and Equilibration methods for the determination of $\mathbf{d}_{31}$-palmitic acid oxidation in Man using Continuous Flow Isotope Ratio Mass Spectrometry

Valérie Sauvinet ${ }^{1,2^{*}}$, Laure Gabert ${ }^{1,4}$, Maud Alligier ${ }^{1,2}$, Sylvie Normand ${ }^{1,3}$, Hubert Roth $^{1,5}$, Martine Laville $e^{1,2,3,4}$ and Michel Désage ${ }^{1,3}$

${ }^{1}$ Lyon University, CRNH Rhône-Alpes and Center for European Nutrition, Safety and health, F-69310 Pierre Bénite, France.

${ }^{2}$ INSERM U1060, CarMen Laboratory, F-69921 Oullins, France

${ }^{3}$ Lyon University, F-69310 Lyon Pierre Bénite, France

${ }^{4}$ Hospices Civils de Lyon, F-69310 Pierre Bénite, France

${ }^{5}$ INSERM U1055, CHU Grenoble, F-38043 Grenoble, France

*Correspondence to: Valérie Sauvinet, Centre de Recherche en Nutrition Humaine RhôneAlpes (CRNH-RA) and CENS, Centre Hospitalier Lyon Sud, Centre de Biologie et Anatomie Pathologie du Sud (CBAPS), Bât. 3D

165 chemin du Grand Revoyet, 69310 Pierre Bénite, France; phone number: +33 (0)4 7886 29 81; fax number: +33 (0)4 788666 54; valerie.sauvinet@ chu-lyon.fr 


\begin{abstract}
250 words max
During nutritional interventions, the ingestion of $\mathrm{d}_{31}$-palmitic acid and $\mathrm{H}_{2}{ }^{18} \mathrm{O}$ allows assessment of dietary fatty acid oxidation from cumulative ${ }^{2} \mathrm{H}$ recovery in urine and estimation of the total body water pool (TBW) from ${ }^{18} \mathrm{O}$ dilution. Continuous flow - isotope ratio mass spectrometry (CF-IRMS) coupled to either equilibration or high temperature conversion techniques (HTC) permits ${ }^{2} \mathrm{H}$ and ${ }^{18} \mathrm{O}$ enrichment measurements in biological fluids. Thus it was of great interest to compare these methods applied to the determination of dietary fatty acid oxidation.

Linearity, accuracy and correlation between CF-equilibration and CF-HTC were first checked using ${ }^{2} \mathrm{H}$ - and ${ }^{18} \mathrm{O}$ - enriched water and urine samples. Urine samples from 14 subjects were then measured with both methods. ${ }^{2} \mathrm{H}$ - and ${ }^{18} \mathrm{O}$ - raw data were normalised against calibration lines. The final aim was to study the impact of normalised raw results on physiological data (i.e. TBW and $\mathrm{d}_{31}$-palmitate recovery).

No significant difference was observed between $\delta^{18} \mathrm{O} \%$ and $\delta^{2} \mathrm{H} \%$ o enrichment measurements depending on the analytical method used. Volumes of TBW calculated from $\delta^{18} \mathrm{O} \%$ o enrichments measured either with $\mathrm{CF}$-equilibration or CF-HTC were not significantly different with respectively $45.2 \pm 1.0 \mathrm{~L}$ or $45.7 \pm 1.0 \mathrm{~L}$ (mean \pm sem, $\mathrm{p}=0.09$ ). Palmitic acid oxidation results obtained from $\delta^{2} \mathrm{H} \%$ o enrichment measurements and TBW from CFequilibration vs CF-HTC were not significantly different $(\mathrm{p} \geq 0.26)$ with respectively $16.2 \pm 1.6 \%$ vs $16.2 \pm 1.1 \%$ at $8 \mathrm{~h}, 18.7 \pm 2.0 \%$ vs $17.6 \pm 1.3 \%$ at $12 \mathrm{~h}$ and $21.7 \pm 1.9 \%$ vs $21.5 \pm 1.3 \%$ at 3 days post-dose (mean \pm sem).

Thus, even if CF-HTC was preferred because it was more practical to carry out, both methods allow study of dietary lipid oxidation in man and generate similar results.
\end{abstract}

\title{
Abbreviated title (up to 70 characters): \\ HTC or Equilibration for the determination of fatty acid oxidation
}

Key words (5 maxi): deuterium; oxygen-18; continuous flow - isotope ratio mass spectrometry; equilibration; high temperature conversion. 


\section{INTRODUCTION}

Stable isotopes are useful tools to study human metabolism in many situations. ${ }^{[1]}$ Body composition $^{[2]}$ and total energy expenditure (TEE) ${ }^{[3]}$ can be measured by mass spectrometry using stable isotope labelled water, while the metabolism of proteins, lipids and carbohydrates can be measured using the appropriate labelled tracers $\left(\right.$ e.g. ${ }^{2} \mathrm{H}-,{ }^{13} \mathrm{C}$ - or ${ }^{15} \mathrm{~N}$ - amino acids, ${ }^{[4,5]}$ ${ }^{2} \mathrm{H}$ - or ${ }^{13} \mathrm{C}$ - glucose, ${ }^{[6,7] 2} \mathrm{H}$ - or ${ }^{13} \mathrm{C}$ - fatty acids $\left.{ }^{[8]}\right)$.

Assessing dietary fatty acid oxidation is of major importance during nutritional interventions. The conventional method using ${ }^{13} \mathrm{C}$-labelled fatty acids ${ }^{[9]}$ required measurement of ${ }^{13} \mathrm{C}$-enrichment in exhaled $\mathrm{CO}_{2}$ and determination of total $\mathrm{CO}_{2}$ production $\left(\mathrm{V}_{\mathrm{CO} 2}\right)$ by indirect calorimetry. Moreover an acetate correction factor was required due to ${ }^{13} \mathrm{C}$ sequestration in the tricarboxylic (TCA) cycle. ${ }^{[10]}$ In 2001, Votruba et al. ${ }^{[11]}$ validated a simpler method using palmitic acid uniformly labelled with deuterium atoms (ie $\mathrm{d}_{31}$-palmitic acid) and ${ }^{18} \mathrm{O}$-labelled water. During $\mathrm{d}_{31}$-palmitic acid oxidation, the ${ }^{2} \mathrm{H}$ label is removed from fatty acids during $\beta$-oxidation and TCA cycle. The deuterium atoms appear as ${ }^{2} \mathrm{H}_{2} \mathrm{O}$ which mixes with the body water pool, providing a cumulative record of fat oxidation, while ${ }^{18} \mathrm{O}$ dilution gives the total body water (TBW) estimation. With this method, only urine samples need to be collected. $\mathrm{V}_{\mathrm{CO} 2}$ determination and acetate correction for the calculation of recovery are no longer needed and experimentation can be performed in free-living conditions, unlike the conventional method which requires that volunteers stay at the clinical investigation center for measuring respiratory gas exchanges $\left(\mathrm{V}_{\mathrm{CO} 2}\right)$ by indirect calorimetry.

Continuous flow - isotope ratio mass spectrometry (CF-IRMS) allows ${ }^{2} \mathrm{H}$ and ${ }^{18} \mathrm{O}$ enrichment measurements in biological fluids (plasma, saliva and urine). According to the method used, samples are converted into gaseous hydrogen, carbon dioxide or carbon monoxide carried by helium carrier gas inside the mass spectrometer source. Among commercially available devices, two methods are traditionally used: gas/liquid equilibration ${ }^{[12-14]}$ and carbon supported-high temperature conversion. ${ }^{[15-17]}$

Principle of continuous flow gas/liquid equilibration method remains the same since the works of Epstein and Mayeda in 1953, ${ }^{[18]}$ Rolston et al. in 1976, ${ }^{[19]}$ or Horita et al. in $1989,{ }^{[20]}$ using off-line devices: $\mathrm{H}_{2} \mathrm{O}$ from biological fluids is equilibrated either with $\mathrm{CO}_{2}$ gas or with $\mathrm{H}_{2}$ gas in the presence of platinum to catalyze equilibration. ${ }^{[13]}$ Initially dedicated to water, CF-equilibration was also used in complex matrix like urine and plasma in our laboratory ${ }^{[21-23]}$ and other teams. ${ }^{[13,24,25]}$

With carbon supported-high temperature conversion, the underlying principle is the Unterzaucher reaction. ${ }^{[26]}$ Water is converted in $\mathrm{H}_{2}$ and $\mathrm{CO}$ in a glassy carbon reactor heated 
at temperatures well in excess of $1000^{\circ} \mathrm{C} \cdot \mathrm{H}_{2}$ and $\mathrm{CO}$ are then separated on a molecular sieve column and introduced into the isotope ratio mass spectrometer source. Continuous flow high temperature conversion method is widely used for ${ }^{2} \mathrm{H}$ and ${ }^{18} \mathrm{O}$ enrichment measurements in biological fluids. In 2004, Richelle et al. ${ }^{[27]}$ applied this method to the determination of ${ }^{2} \mathrm{H}$ and ${ }^{18} \mathrm{O}$ enrichments measurements in plasma samples of rats. High temperature conversion was then presented as a promising tool to assess body composition and total energy expenditure. In 2006, Ripoche et al. ${ }^{[28]}$ validated the accuracy of ${ }^{2} \mathrm{H}$ and ${ }^{18} \mathrm{O}$ enrichment measurements in urine and plasma samples by comparison to classical dual-inlet methods. A chromium tube was used for ${ }^{2} \mathrm{H}$ reduction, and a glassy carbon reactor for ${ }^{18} \mathrm{O}$ pyrolysis. More recently, high temperature conversion of $\mathrm{H}_{2} \mathrm{O}$ from urine and saliva was validated using a glassy carbon reactor ${ }^{[29]}$.

Although equilibration and carbon supported-HTC techniques are well described in the literature, these two methodologies have never been directly compared for the measurement of ${ }^{2} \mathrm{H}$ and ${ }^{18} \mathrm{O}$ enrichments in urine samples. The principles are fundamentally different. With the equilibration technique, the measurement is performed on the gas resulting from the isotopic equilibrium between $\mathrm{H}_{2} \mathrm{O}$ from the sample and the added equilibration gas. With the HTC technique, results are produced directly from the liquid sample reaction in the glassy carbon reactor. To facilitate the reading, in the following of this paper, carbon supported-HTC was replaced by HTC and corresponds to the method of high temperature conversion supported by a glassy carbon reactor.

This essay critically examines the two methods and their practicability with large series of samples, which are current in nutritional intervention protocols in man. In this paper, we first checked the agreement of results obtained from IAEA (International Atomic Energy Agency) reference waters (SLAP2, GISP and VSMOW2) and from ${ }^{2} \mathrm{H}$ - and ${ }^{18} \mathrm{O}$ - enriched water or urine samples using both methods. Then the results obtained with urine samples from 14 subjects, who participated in a nutritional intervention, were compared using either continuous flow -equilibration or -HTC. The final aim was to study the impact of the raw results (i.e. analytical results which are ${ }^{2} \mathrm{H}$ and ${ }^{18} \mathrm{O}$ normalised enrichments expressed in $\delta \%$ ) on physiological data (i.e. TBW and $\mathrm{d}_{31}$-palmitic acid recovery).

\section{EXPERIMENTAL}




\section{Samples}

\section{Preliminary tests}

Linearity and accuracy tests between CF-equilibration and CF-HTC techniques for $\delta^{2} \mathrm{H} \%$ and $\delta^{18} \mathrm{O} \%$ onrichment measurements were performed using reference waters SLAP2 (Standard Light Antartic Precipitation, $\delta^{18} \mathrm{O}=-55.5 \% \circ, \delta^{2} \mathrm{H}=-428.8 \% \circ$ ), GISP (Greenland Ice Sheet Precipitation, $\delta^{18} \mathrm{O}=-24.8 \%$ o, $\delta^{2} \mathrm{H}=-189.5 \%$ ) and VSMOW2 (Vienna Standard Mean Ocean Water, $\delta^{18} \mathrm{O}=0.0 \%$, $\delta^{2} \mathrm{H}=0.0 \%$ ) from the International Atomic Energy Agency (IAEA, Vienna, Austria), as well as ${ }^{2} \mathrm{H}$ - and ${ }^{18} \mathrm{O}$-enriched waters. The correlation between equilibration- and HTC- data was evaluated with the analysis of ${ }^{2} \mathrm{H}$ - and ${ }^{18} \mathrm{O}$ - enriched water and urine samples. Eight water samples and nine urine samples were enriched with increasing quantities of ${ }^{2} \mathrm{H}_{2} \mathrm{O}$ (99\% enriched) and $\mathrm{H}_{2}{ }^{18} \mathrm{O}$ (10\% enriched, Eurisotop, Saint Aubin, France). Dilutions were prepared gravimetrically. Final enrichments of water samples were previously determined by repetitive measurements against reference waters from IAEA and were used as expected values, ranging from $-8.2 \delta \%$ to $220.7 \delta \%$ o for ${ }^{18} \mathrm{O}$ and from $-65.2 \delta \%$ o to $1218.3 \delta \%$ o for ${ }^{2} \mathrm{H}$. For urine samples, the averaged enrichments measured in the present study ranged from $-2.7 \delta \%$ o to $200.6 \delta \%$ or for ${ }^{18} \mathrm{O}$ and from $-21.1 \delta \%$ o to $1814.4 \delta \%$ ofor ${ }^{2} \mathrm{H}$.

\section{Protocol}

Isotopic enrichments were measured in urine samples from 14 subjects. The subjects were fully informed of the purpose and potential risks of the experimental protocol. Individual informed written consents were obtained before the study which was approved by the Scientific Ethics Committee of Lyon (CPP Sud Est II). After collection of baseline urine samples, the subjects ingested $0.5 \mathrm{~g} \cdot \mathrm{kg}^{-1}$ of $\mathrm{H}_{2}{ }^{18} \mathrm{O}$ (10\% enriched) to measure total body water. They then ingested a breakfast in which $20 \mathrm{mg} \mathrm{kg}^{-1}$ of $\left[\mathrm{d}_{31}\right]$-palmitic acid ( $>98 \%$ enriched, i.e. $98 \%$ of palmitic acid molecules were labelled with 31 deuterium atoms, Eurisotop) were homogenized. Following ingestion of the meal, hourly urine samples were collected for $12 \mathrm{~h}$, and on days 1, 2 and 3 post-dose. Equilibration time in the body water pool for $\mathrm{H}_{2}{ }^{18} \mathrm{O}$ was taken at $4 \mathrm{~h}$ and $5 \mathrm{~h}$ post-dose. In order to determine the body water pool size, a dilution of the $\mathrm{H}_{2}{ }^{18} \mathrm{O}$ dose ingested was performed gravimetrically for each subject in Evian water (Dil.), in such a way as to obtain $\delta^{18} \mathrm{O} \%$ enrichments similar to those in urine samples after tracer ingestion. Results from this sample determined the dilution factor of ${ }^{18} \mathrm{O}$ in the body, and consequently TBW. The determination of $\left[\mathrm{d}_{31}\right]$-palmitic acid oxidation rate required the collection of 13 urine samples. ${ }^{2} \mathrm{H}$ enrichment measurements were performed on all samples, whereas three urine samples and the diluted solution of the labelled water were analysed for 
their ${ }^{18} \mathrm{O}$ content. No further details on clinical part of the protocol will be provided here, insofar as the subject of this paper is to compare two analytical methods, and not to discuss the results of the study which are to be published later.

\section{Sample processing}

Urine samples $(2 \mathrm{ml})$ were decolorized with dry black carbon $(20 \mathrm{mg})$, filtered $(0.45 \mu \mathrm{m}$, cellulose acetate membrane, Macherey Nagel, Hoerd, France) and stored at $-20^{\circ} \mathrm{C}$ until analysis. Water samples were analysed without purification.

\section{Continuous Flow Equilibration}

Continuous flow equilibration analyses were performed using a Multiflow system connected to an Isoprime IRMS (Isoprime Ltd, Cheadle, UK). $200 \mu \mathrm{L}$ of standard water, ${ }^{2} \mathrm{H}$ and ${ }^{18} \mathrm{O}$ enriched water or filtered urine sample were loaded in Labco Exetainer ${ }^{\circledR}$ vials with screw caps and pierceable rubber septum (16.5mm, Labco Limited, Buckinghamshire, UK). A platinum catalyst (Hokko coils, Elementar, Villeurbanne, France) was inserted into vials for the hydrogen equilibration process to speed up the hydrogen isotope exchange reaction between water and $\mathrm{H}_{2}$ gas. ${ }^{[30]}$ Hokko coil catalysts were washed with deionised water and conditioned at $80^{\circ} \mathrm{C}$ for 8 hours before use. Vials were placed in a temperature-controlled rack $\left(40^{\circ} \mathrm{C} \pm 0.1^{\circ} \mathrm{C}\right)$ offering 60 locations and filled either with $\mathrm{CO}_{2} / \mathrm{He}(5 \%)$ or $\mathrm{H}_{2} / \mathrm{He}(10 \%)$. The equilibration times recommended by the manufacturer were $4 \mathrm{~h} 30$ for $\mathrm{CO}_{2}$ or $1 \mathrm{~h} 30$ for $\mathrm{H}_{2}$. Taking into account the autofilling time with equilibration gas (150sec /vial, at least 54 vials in the rack), the real equilibration times were actually $4 \mathrm{~h} 30$ for $\mathrm{CO}_{2}$ and $2 \mathrm{~h} 15 \mathrm{for}_{2}$. Equilibrated gas was then transferred from the vial's headspace to the sample loop $(50 \mu \mathrm{L}$ for $\mathrm{CO}_{2}$ or $100 \mu \mathrm{L}$ for $\left.\mathrm{H}_{2}\right)$ then on a molecular sieve $\mathrm{GC}$ column $\left(90^{\circ} \mathrm{C}, 2.5 \mathrm{~m}, 1 / 8\right.$ inch, 60 $80 \mathrm{mesh}$ ) where all water vapour was separated. The dried gas was then allowed to pass from the water trap (Nafion ${ }^{\circledR}$ membrane) to the isotope ratio mass spectrometer for analysis. The sample peak was followed by one pulse of reference gas $\left(\mathrm{H}_{2}\right.$ grade 5.6 or $\mathrm{CO}_{2}$ grade 5.5). The ${ }^{2} \mathrm{H} /{ }^{1} \mathrm{H}$ ratios were corrected for the $\mathrm{H}_{3}{ }^{+}$effect. ${ }^{[31]}$ Two batches of analyses were performed, one for ${ }^{2} \mathrm{H}$ - and another for ${ }^{18} \mathrm{O}$ - enrichment measurements. To avoid refocusing the mass spectrometer and changing the sample loop between each sequence, all samples from preliminary tests and nutritional intervention were first analysed for their ${ }^{2} \mathrm{H}$ contents and then for their ${ }^{18} \mathrm{O}$ content. Samples were prepared in triplicate for ${ }^{2} \mathrm{H}$ analyses, in duplicate for ${ }^{18} \mathrm{O}$ analyses and were each injected three times. Even if no memory effect was observed using equilibration method, ${ }^{[32]}$ urine samples were analysed in the ascending enrichment order. The total analysis time for 20 samples including the autofilling with equilibration gas, 
equilibration time and analyses, was $15 \mathrm{~h}$ for ${ }^{2} \mathrm{H}$ enrichment measurements and $13 \mathrm{~h}$ for ${ }^{18} \mathrm{O}$ enrichment measurements. The total volume of purified urine required for the ${ }^{2} \mathrm{H}$ - and ${ }^{18} \mathrm{O}$ analysis of each sample was $1 \mathrm{~mL}$.

\section{Continuous Flow High Temperature Conversion}

High temperature conversion analyses were performed using a commercial device consisting of a Thermo AS3000 liquid autosampler, a high-temperature conversion elemental analyser (TCEA) coupled with a Delta Advantage isotope ratio mass spectrometer via a Conflow IV Interface (Thermo Scientific, Bremen, Germany). According to the manufacturer design, the reactor consisted of a glassy carbon tube (OD 12mm, ID 7mm, length $356 \mathrm{~mm}$ ) containing carbon granulates (diameter $\geq 3 \mathrm{~mm}$ ) above a quartz wool pad. This set was inserted in a ceramic tube (OD 17mm, ID 13mm, length 470mm). A stainless steel injector sleeve (opening $\sim 8 \mathrm{~mm}$, length $60 \mathrm{~mm}$ ) was placed at the top of the glassy carbon tube. The following conditions were used: reactor temperature $1420^{\circ} \mathrm{C}, \mathrm{GC}$ column temperature $90^{\circ} \mathrm{C}$ and helium flow from the top of the reactor $90 \mathrm{~mL} / \mathrm{min}$. Standard waters and filtered urine samples were thawed and $300 \mu \mathrm{L}$ aliquots were transferred to a vial for autosampler with an insert (Agilent, Massy, France). The insert was entirely filled with sample in the aim to reduce isotope exchange in the sample container. Aliquots of $0.1 \mu \mathrm{L}$ were injected into the glassy carbon reactor where water from samples was converted into $\mathrm{H}_{2}$ and $\mathrm{CO}$, which were then separated on the molecular sieve GC column $\left(0.6 \mathrm{~m}, 1 / 4 \mathrm{inch}, 5 \mathrm{~A}^{\circ}\right)$. In order to keep optimal separation conditions, GC column was heated to $300^{\circ} \mathrm{C}$ overnight every 2000 injections. Each analytical run consisted of two pulses of the hydrogen reference gas (grade 5.6) followed by elution of $\mathrm{H}_{2}$ (retention time $\left.(\mathrm{RT})=123 \mathrm{sec}\right)$ and $\mathrm{CO}(\mathrm{RT}=183 \mathrm{sec})$ gases from the sample, and then finally by two pulses of carbon monoxide reference gas (grade 4.7). After the elution of the $\mathrm{H}_{2}$ peak, a "peak jump" occurred at 150sec, allowing $\mathrm{CO}$ analysis: ion beams of $\mathrm{m} / \mathrm{z}, 28$ $\left(\mathrm{C}^{16} \mathrm{O}\right)$ and $m / z, 30\left(\mathrm{C}^{18} \mathrm{O}\right)$ were then focused to specific Faraday cups by a rapid change in the magnetic field strength. The ${ }^{2} \mathrm{H} /{ }^{1} \mathrm{H}$ ratios were corrected for the $\mathrm{H}_{3}{ }^{+}$effect. ${ }^{[31]}$ Inter-samples memory effects have been reported for water analyses using the high temperature conversion of water on glassy carbon. Precautions were taken to minimize this well-documented effect: ${ }^{[27,28,32,33,34,35]}$ I) the sample was injected after 3 pull-ups, (II) the needle of the $1 \mu \mathrm{L}$ syringe was left in the heated injector for $10 \mathrm{sec}$ after the injection, (III) urine samples were analysed in ascending enrichment order and finally, (IV) for each sample, five consecutive injections were done in a single run, and then the sample was injected once in five consecutive runs. Only the last four runs were used for calculations. In these conditions, the total analysis time for 20 samples was $16 \mathrm{~h}$ for both isotopes enrichment 

each sample was $300 \mu \mathrm{L}$, each sample injection requiring only $0.1 \mu \mathrm{L}$.

\section{Corrections, calibration and order of samples analysis}

${ }^{2} \mathrm{H}$ and ${ }^{18} \mathrm{O}$ enrichments were expressed in $\delta \%$ vs VSMOW. Laboratory water (Evian $®$, Evian, France) was analysed at the beginning and the end of each sequence. Raw data obtained from these samples were used to calculate the drift value due to the long period of analysis. Using this value and the forecast function of the software Excel (pack Office 2002, Microsoft $\left({ }^{\circledR}\right)$, the drift-correction was applied to each sample of a same batch of analyses. Calibration was the same for the samples from preliminary tests and for those from the nutritional intervention. Three water standards from Iso-analytical Limited (Cheshire, UK; IA $\mathrm{R} 053, \delta^{18} \mathrm{O}=-10.18 \%$ 。, $\delta^{2} \mathrm{H}=-61.7 \%$; IA R054, $\delta^{18} \mathrm{O}=0.56 \%, \delta^{2} \mathrm{H}=4.93 \%$ and IA R055 , $\delta^{18} \mathrm{O}=108.63 \%$, $\delta^{2} \mathrm{H}=843.43 \%$ relative to VSMOW) were used to establish the calibration curve for normalisation of the values. For both techniques, the isotopic composition of enriched waters and urine samples was calculated from raw data using the linear regression equation obtained from known and measured values of these water standards.

Concerning the order of samples analysis, for both techniques, ${ }^{2} \mathrm{H}$ - and ${ }^{18} \mathrm{O}$ - enriched waters, reference waters from IAEA and standard waters from preliminary tests were analysed in the ascending enrichment order. ${ }^{2} \mathrm{H}$ - and ${ }^{18} \mathrm{O}$ - enriched urine samples and samples from nutritional intervention were measured as following for both methods: laboratory water was first measured, then standard waters in the ascending enrichment order. Another laboratory water was injected to avoid memory effect on the following urine samples which were injected in the ascending enrichment order. Finally laboratory water was measured a last time for the drift correction.

\section{Calculations}

The oxidation rate of palmitic acid was inferred from the cumulative recovery of ${ }^{2} \mathrm{H}$ in total body water (TBW) according to Votruba et al.: ${ }^{[11]} \mathrm{TBW}$ was determined using the ${ }^{18} \mathrm{O}$ isotope dilution method. ${ }^{[2]}$ First, the equation (1) allowed $\mathrm{H}_{2}{ }^{18} \mathrm{O}$ dilution space calculation from baseline and $4 \mathrm{~h}$ or $5 \mathrm{~h}$ urine samples, plus dilution of the ingested dose and Evian water which were analysed in the same batch.

$$
N(m o l)=\left(\frac{D_{H_{2}^{18} \mathrm{O}} \times V_{\text {Dil }}}{M W_{\mathrm{H}_{2} \mathrm{O}} \times v_{\mathrm{H}_{2}{ }^{18} \mathrm{O}}}\right) \times\left(\frac{\delta^{18} O_{\text {Dil }}-\delta^{18} O_{\text {Evian }}}{\delta^{18} O_{T 4 \text { or } 5 h}-\delta^{18} O_{\text {basal }}}\right)
$$


$N$ is the pool space in moles (i.e. the oxygen dilution space), $D_{\mathrm{H}_{2}{ }^{18} \mathrm{O}}$ is the weight of labelled water administered in $\mathrm{g}, V_{\text {Dil }}$ is the total amount of water (Evian $+\mathrm{H}_{2}{ }^{18} \mathrm{O}$ ) used to dilute the labelled water in $\mathrm{g}, v_{\mathrm{H}_{2}{ }^{18} \mathrm{O}}$ is the labelled water diluted for analysis in $\mathrm{g}, \mathrm{MW}_{\mathrm{H}_{2} \mathrm{O}}$ is the molecular weight of water in g.mol ${ }^{-1}$; and $\delta^{18} \mathrm{O}$ is the enrichment in \%० of the diluted labelled water for analysis (Dil.), dilution water (Evian), post-dose sample (T4 or 5h, the maximum $\delta^{18} \mathrm{O} \%$ enrichment was used for calculations), and pre-dose baseline (basal). Next, using the equation (2), TBW was deduced from the dilution space of ${ }^{18} \mathrm{O}(\mathrm{N})$ after adjusting it by a factor of 1.007. Indeed, it is established that the dilution space of ${ }^{18} \mathrm{O}$ is $1.007 \%$ greater than the water space. ${ }^{[2]}$

$$
T B W(L)=\frac{N \times M W_{\mathrm{H}_{2} \mathrm{O}}}{1.007 \times 1000}
$$

Finally, recovery of deuterium from palmitic acid oxidation was calculated as indicated by equation (3)

$$
\% \text { Recovery }=100 \times \frac{\left(T B W \times 2 \times \Delta \delta \times R_{S T D} / 1000\right)}{(D \times P \times n / M W \times 100)}
$$

$\Delta \delta$ was the urine $\delta^{2} \mathrm{H}$ in excess compare to basal and was expressed in \%o ("basal" being ${ }^{2} \mathrm{H} \%$ o enrichment from urine before the ingestion of the tracer) $\mathrm{R}_{\mathrm{STD}}$ was the ${ }^{2} \mathrm{H} /{ }^{1} \mathrm{H}$ ratio of SMOW, $\mathrm{D}$ was the amount of ingested $\mathrm{d}_{31}$-palmitic acid in $\mathrm{g}, \mathrm{P}$ was the ${ }^{2} \mathrm{H}$ isotope atom $\%$ of $\mathrm{d}_{31^{-}}$ palmitic acid, $\mathrm{n}$ was the number of labelled atoms per molecule, and MW was the molecular weight of $\mathrm{d}_{31}$-palmitic acid in g.mol ${ }^{-1}$.

\section{Statistical analysis}

Regarding the raw data from the 14 subjects, a Bland and Altman ${ }^{[36]}$ test was used to evaluate differences between $\delta^{18} \mathrm{O}$ enrichments measured using either high temperature conversion or equilibration. A mixed model was used for $\delta^{2} \mathrm{H}$ enrichment comparison. Significant differences between TBW obtained from $\delta^{18} \mathrm{O}$ measurements with equilibration or HTC techniques were tested using a paired Student test. Cumulative recoveries of $\mathrm{d}_{31}$-palmitic acid obtained from $\delta^{2} \mathrm{H}$ and $\delta^{18} \mathrm{O}$ measurements with equilibration or HTC techniques were tested using a paired Student test and finally, a Bland and Altman test was used to evaluate differences between recoveries of $\mathrm{d}_{31}$-palmitic acid 3 days after the ingestion of the tracer according to the analytical method used. The analyses were performed with Statview (Abacus 


\section{Linearity}

Table 2 shows regression parameters calculated from theoretical enrichments against measured values in enriched waters, both expressed in $\delta \%$. The coefficients of determination were greater than or equal to 0.9999 . Linearity of ${ }^{2} \mathrm{H}$ - and ${ }^{18} \mathrm{O}$ - enrichment measurements was as satisfying for equilibration measurements as for HTC measurements and the same is true for ${ }^{2} \mathrm{H}$ - and ${ }^{18} \mathrm{O}$-measurements. Data were comparable with those published elsewhere. ${ }^{[12,13,29]}$

\section{Accuracy}

Table 3 shows individual accuracy data calculated from ${ }^{2} \mathrm{H}$ and ${ }^{18} \mathrm{O}$ enrichment measurements of enriched waters presented in Table 1 . The means of accuracy results obtained for the whole range of ${ }^{18} \mathrm{O}$ - enrichments were $-0.54 \pm 0.30 \%$ and $-0.39 \pm 0.34 \%$ o when samples were measured by $\mathrm{CF}$-equilibration or CF-HTC respectively. For the whole range of ${ }^{2} \mathrm{H}$ - enrichments, the means of accuracy results were respectively $-1.00 \pm 3.33 \%$ and $-1.52 \pm 3.39 \%$ when samples were measured by $\mathrm{CF}$-equilibration or CF-HTC respectively. The difference from the expected value was smaller for ${ }^{18} \mathrm{O}$ enrichment measurements and remained under $1.80 \%$. Results were less favourable for ${ }^{2} \mathrm{H}$ enrichment measurements and reached $8.51 \%$. Accuracy results were similar between both methods (t-test, $\mathrm{p}>0.1$ ). They corresponded to the level of accuracy reported in the literature ${ }^{[27,28]}$ and remained acceptable. 


\section{Correlation between equilibration- and HTC-CF-IRMS}

Table 4 presents the correlation parameters between data obtained with the equilibration technique and the HTC technique, for $\delta^{18} \mathrm{O} \%$ o measurements and for $\delta^{2} \mathrm{H} \%$ measurements in water samples and in urine samples of increasing enrichments. Expected enrichments were in a range of $-55.5 \delta \%$ o to $220.7 \delta \%$ for ${ }^{18} \mathrm{O}$ and of $-428.0 \delta \%$ o to $1218.3 \delta \%$ o for ${ }^{2} \mathrm{H}$ in water samples (including IAEA reference waters). For urine samples, averaged enrichments measured in this study ranged from $-2.7 \delta \%$ o to $200.6 \delta \%$ or for ${ }^{18} \mathrm{O}$ and from -21.1 to $1814.4 \delta \%$ o for ${ }^{2} \mathrm{H}$. The slopes were respectively 1.0030 and 1.0049 for ${ }^{2} \mathrm{H}$ - and ${ }^{18} \mathrm{O}$ - measurements in water samples, and respectively 0.9993 and 0.9948 for ${ }^{2} \mathrm{H}$ - and ${ }^{18} \mathrm{O}$ - measurements in urine samples. The coefficients of correlation $\mathrm{R}$ were 1.0000 in all cases. Thus, there is excellent agreement between the two introduction systems and this is true whatever the isotope $\left({ }^{2} \mathrm{H}\right.$ or ${ }^{18} \mathrm{O}$ ) or sample nature. It should be noted however that the intercepts were different according to the sample type (water or purified urine). When measurements were performed on water samples, the intercepts were respectively 0.0558 and -1.4604 for ${ }^{2} \mathrm{H}-$ and ${ }^{18} \mathrm{O}$ - measurements. With urine samples, the intercepts were 0.7228 for ${ }^{18} \mathrm{O}$ and 8.4954 for ${ }^{2} \mathrm{H}$-measurements, suggesting a bias between the 2 methods. In the case of measurements by HTC, the entire sample is injected into the reactor. Indeed, one fundamental difference between equilibration and HTC is that the equilibration reaction takes place between the equilibration gas and the $\mathrm{H}_{2} \mathrm{O}$ molecules of the samples, whereas HTC measurements involve a bulk analysis of the sample including water. Some authors used a larger amount of black carbon to purify urine samples. ${ }^{[28]}$ An insufficient purification of urine samples may explain this result. This could be a serious drawback if the accurate isotopic contents were needed. But in metabolic studies performed in the field of nutrition, the measured enrichments in biological samples are always compared to a basal value measured in a sample of same type before the tracer ingestion. This is true for the calculation of Total Body Water, ${ }^{[2]}$ Total Energy Expenditure, ${ }^{[3]}$ or Dietary Fat Oxidation, ${ }^{[11]}$ using ${ }^{2} \mathrm{H}$ - and/or ${ }^{18} \mathrm{O}$ - labelled water.

\section{Analytical results}

We shall now look at the analytical results from the urine samples of the 14 subjects who took part in the protocol. Analytical results were the normalised $\delta^{18} \mathrm{O} \% \mathrm{o}^{-}$and $\delta^{2} \mathrm{H} \% \mathrm{o}^{-}$enrichments measured by CF-IRMS coupled either to equilibration or HTC. The set of water standards used to normalise the data was included in each sample batch. The equation of the calibration curve was therefore established for each series of analyses, in order to compensate for any changes that might occur during the analytical process (e.g. temperature variation during equilibration, reactor lifetime with HTC). 


\section{$\delta^{18} \mathrm{O} \%$ enrichment measurements}

Figure 1(A) shows the average of $\delta^{18} \mathrm{O} \%$ o enrichments obtained in the urine samples at baseline, before the ingestion of $\mathrm{H}_{2}{ }^{18} \mathrm{O}$ by subjects and at $4 \mathrm{~h}$ and $5 \mathrm{~h}$ post-dose. $\delta^{18} \mathrm{O} \% 0$ enrichments were also measured in the dilution of the labelled water dose (Dil.) ingested by subjects, and in the water used to dilute this dose (Evian). All these measurements enter in the calculation of the volume of TBW using equations (1) and (2). $\delta^{18} \mathrm{O} \%$ enrichments at baseline were found at $-3.8 \pm 0.3 \%$ and $-4.0 \pm 0.3 \%$ o (mean \pm sem) using respectively equilibration or HTC. Equilibration of labelled water in urine was reached after 4 or $5 \mathrm{~h}$ depending on the subjects, and was found at $41.4 \pm 1.3 \%$ and $41.2 \pm 1.3 \%$ using equilibration or HTC respectively for the analyses. The dispersion of $\delta^{18} \mathrm{O} \%$ enrichment measurements, namely, the standard deviation of replicates injection, was greater with the equilibration technique compared with HTC. Standard deviations averaged $0.37 \pm 0.24 \%$ o for all the measurements, and were about 3 times higher than those obtained with thermal conversion elemental analysis $(0.14 \pm 0.20 \%$ o). Nevertheless, for each sample from the 14 subjects, no significant difference was observed depending on the analytical method used (paired t-tests, $p>0.11$ ). A Bland and Altman test (Fig.1(B)) that presents the differences between results from both methods in function of their respective average, showed a good agreement between both methods for $\delta^{18} \mathrm{O} \%$ o enrichment measurements with a mean bias of $0.12 \%$ and a confidence interval of differences between -3.51 and $+3.27 \%$ o. Further purification of urine samples should reduce the bias between the two methods, including increasing the amount of black carbon. This step appears to be essential to obtain good quality of analyses using HTC.

\section{$\delta^{2} H \%$ enrichment measurements}

The evolution of deuterium enrichment in urines samples until 3 days after ingestion of $\mathrm{d}_{31}$ palmitic acid is presented in Figure 2. $\delta^{2} \mathrm{H} \%$ o enrichment in urine continuously increased until the end of the test, sharply from 60 to 480min after ingestion of the deuterated fatty acid, and moderately after $480 \mathrm{~min}$. A plateau was reached during the last 2 days. As can be seen from Fig.2(A), the results for one subject show that the dispersion of $\delta^{2} \mathrm{H} \%$ o enrichment measurements was greater with the equilibration technique than with high temperature conversion. Standard deviations averaged $7.26 \pm 2.11 \%$ and were about 16 times higher than those obtained with HTC technique $(0.45 \pm 0.23 \%$ o. The fact that each sample vial was injected several times may explain this dispersion problem with equilibration method. Indeed, the repeated injections from a same vial result in a decrease of the signal amplitude. No more 
than three injections are possible using $\mathrm{H}_{2} \mathrm{O} / \mathrm{H}_{2}$ equilibration. Moreover, due to the device configuration, the number of vial for each sample was limited to 3 in order to analyse all samples from one subject (see Experimental part). Nevertheless, Fig.2(B) provides the results for the 14 subjects and shows that the average values of deuterium enrichments in delta \%o were homogeneous. The previous observation was confirmed by applying a mixed model which did not show any significant differences between the two methods for $\delta^{2} \mathrm{H} \%$ 。 measurement ( $\mathrm{p}=0.513)$. Using equilibration, results are dependent on the parameters influencing the isotopic exchange process between liquid and gaseous phases, i.e. temperature and catalyst efficiency. These two parameters are not easy to control. Due to the temperaturedependent fractionation factor of hydrogen between liquid and gas phases, a temperature variation of only $1{ }^{\circ} \mathrm{C}$ during the equilibration process can cause a difference of $6 \%$ on $\delta^{2} \mathrm{H} \%$ 。 measurement ${ }^{[37,38]}$ Little information is available concerning the catalyst life time and its regeneration. A lower efficiency of catalysts used in this study could have been the cause of the large dispersion of deuterium enrichment measurement using equilibration. However the enriched water samples from preliminary tests (Table 1) were measured using new platinum catalysts with $\mathrm{H}_{2} \mathrm{O} / \mathrm{H}_{2}$-equilibration method, and the standard deviations remain important in the same way as standard deviations from samples of the nutritional intervention.

\section{Conclusion}

$\delta^{2} \mathrm{H}$ and $\delta^{18} \mathrm{O}$ in urine samples can be analysed using either equilibration or HTC-CF-IRMS. Both methods were perfectly correlated and linearity of measurements was excellent in a range of $-55.5 \delta \%$ to $220.7 \delta \%$ ofor ${ }^{18} \mathrm{O}$, and of $-428.0 \delta \%$ to $1218.3 \delta \%$ for ${ }^{2} \mathrm{H}$. Accuracy of ${ }^{2} \mathrm{H}$ - and ${ }^{18} \mathrm{O}$ - measurements was acceptable for both techniques. Concerning high temperature conversion, one disadvantage which is largely described in the literature is the memory effect. ${ }^{[27,34,32]}$ With a regular maintenance of the reactor (every 2000 injections) and by taking the various precautions described in the experimental section, this paper shows that it is possible to obtain results with limited analytical variation and without any modification of the high-temperature reactor. ${ }^{[34]}$ But this has a cost. Indeed consumables used to the maintenance of the reactor are expensive. The volume of sample required with HTC method is reduced compared to equilibration method. That can be a great advantage when urine samples have to be collected in specific populations as new-born, or people with handicap (intellectual and/or motor). Regarding the duration of the analyses (see Experimental part), time saving with HTC method is real compared to equilibration method, provided that ${ }^{2} \mathrm{H}$ and ${ }^{18} \mathrm{O}$ enrichment measurements are necessary for all samples analysed. Indeed, for a same number of samples to measure, if only one isotope is needed, the duration of analyses is roughly equivalent. 


\section{Physiological results}

\section{Volume of total body water}

Volumes of TBW were calculated from $\delta^{18} \mathrm{O} \%$ enrichments measured either with the equilibration device or the HTC device using the equations (1) and (2) described in the experimental section. Individual results (Figure 3(A)) show differences of up to $2.2 \mathrm{~L}$ and the results from 8 of 14 subjects show TBW differences less than or equal to $1 \mathrm{~L}$. The mean difference in the volume of TBW for each subject was $1.0 \pm 0.7 \mathrm{~L}$ (mean $\pm \mathrm{SD}$ ) depending on the analytical method. Finally, for the 14 subjects, the volume of TBW calculated with the data obtained using equilibration or HTC were respectively 45.1 $\pm 1.0 \mathrm{~L}$ and $45.7 \pm 1.0 \mathrm{~L}$ (mean \pm sem, Figure $3(\mathrm{~B}))$. Thus, volume of TBW does not depend on the technique used for $\delta^{18} \mathrm{O}$ enrichments. This was confirmed by applying a paired t-test $(\mathrm{p}=0.0869)$.

\section{Dietary fatty acid oxidation}

Figure 4 shows the $8 \mathrm{~h}, 12 \mathrm{~h}$ and 3 day cumulative percentage recoveries of $\mathrm{d}_{31}$-palmitic acid in urine samples from the 14 subjects calculated with the data coming from the equilibration or from the HTC device. The calculation of palmitic acid oxidation (See equation (3), experimental section) required deuterium enrichment measurements in urine and the volume of total body water, obtained previously through $\delta^{18} \mathrm{O} \%$ enrichment measurements. As shown in Figure 4(A), the recovery rate of deuterium in urine at $8 \mathrm{~h}, 12 \mathrm{~h}$ and 3 days post-dose were respectively $16.2 \pm 1.6 \%$ vs $16.2 \pm 1.1 \%, 18.7 \pm 2.0 \%$ vs $17.6 \pm 1.3 \%$ and $21.7 \pm 1.9 \%$ vs $21.5 \pm 1.3 \%$ (mean \pm sem, data from equilibration $v s$ HTC). A paired t-test showed no significant difference for $\mathrm{d}_{31}$-palmitic acid recovery calculated either from the equilibration data or the HTC data, at $8 \mathrm{~h}(\mathrm{p}=0.9715), 12 \mathrm{~h}(\mathrm{p}=0.2616)$ and 3 days post-dose $(\mathrm{p}=0.8840)$. A Bland and Altman test (Fig.4(B)) shows differences between results from both methods as a function of the average of results obtained with each method. This diagram shows a mean bias of $-0.14 \%$ according the analytical methods used, with a confidence interval between -6.39 to $+6.75 \%$. Thus, both methods allow study of dietary lipid oxidation in man and generate similar results. Analytical variations remained lower than inter-subject variations.

\section{CONCLUSIONS}

A series of experiments conducted in this study indicated that $\delta^{2} \mathrm{H}$ and $\delta^{18} \mathrm{O}$ in urine samples can be analysed using either equilibration-CF-IRMS or HTC-CF-IRMS. Both methods were perfectly correlated, accuracy was acceptable and the linearity of enrichment 
measurements was excellent for enrichments usually encountered in the field of human nutrition. With the equilibration method, the dispersion of measurements is much greater than when using HTC.

Applying these methods to the determination of $\mathrm{d}_{31}$-palmitic acid oxidation resulted in similar results and no significant difference was observed for fatty acid recovery and total body water volume.

${ }^{2} \mathrm{H}$ and ${ }^{18} \mathrm{O}$ enrichment measurements in biological fluids have numerous applications in the field of nutrition. Indeed, measuring TBW also enables study of body composition; ${ }^{[39]}$ ${ }^{2} \mathrm{H}$ and ${ }^{18} \mathrm{O}$ elimination rate calculation after doubly-labelled water ingestion allows for the determination of total energy expenditure. ${ }^{[3]}$ Showing that these measurements are equivalent using two commercially available devices based on fundamentally different principles is of great interest.

Regarding the practical aspect of the two methods, due to the isotopic exchange process, the equilibration method is expected to be less sensitive to impurities from biological samples. However deuterium enrichment determination depends on the efficiency of the catalyst. Large volumes of samples are required and the method is time-consuming because of the necessity to analyse the biological samples for ${ }^{2} \mathrm{H}$ - and then ${ }^{18} \mathrm{O}$ - content. Conversely, HTC gives ${ }^{2} \mathrm{H}$ - and ${ }^{18} \mathrm{O}$ - enrichment results in the same run.

Despite the drawbacks of the HTC method which include memory effects, limited reactor lifetime and the cost of consumables, high temperature conversion analysis rather than equilibration for measuring $\delta^{2} \mathrm{H}$ and $\delta^{18} \mathrm{O}$ enrichments in urines remains more convenient for clinical studies where the number of samples for each subject is often high. However, it is important to follow instructions to minimise inter-sample memory effects and special attention should be paid to sample purification when analyses are performed using HTC. Even if measured enrichments in biological samples are always compared to a basal value in metabolic studies performed in the field of nutrition. 


\section{Acknowledgements}

We are indebted to all the staff of the Centre de Recherche en Nutrition Humaine RhôneAlpes for their technical assistance in subject recruitment, sample collection and sample preparation. We also thank Dr Stéphane Blanc, Dr Julie-Anne Nazare and the anonymous reviewers for revising the manuscript and providing useful advice, as well as Lynn Richardson for language revision. 


\section{REFERENCES}

[1] G.G. Dolnikowski, J.B. Marsh, S.K. Das, F.K. Welty. Stable isotopes in obesity research. Mass Spectrom. Rev. 2005, 24, 311.

[2] D.A. Schoeller, E. van Santen, D.W. Peterson, W. Dietz, J. Jaspan, P.D. Klein. Total body water measurement in humans with ${ }^{18} \mathrm{O}$ and ${ }^{2} \mathrm{H}$ labeled water. Am. J. Clin. Nutr. 1980, 33, 2686.

[3] D.A. Schoeller, E. Ravussin, Y. Schutz, K.J. Acheson, P. Baertschi, E. Jéquier. Energy expenditure by doubly labeled water: validation in humans and proposed calculation. Am. J. Physiol. 1986, 250, R823.

[4] J.-P. Godin, A.-F. Mermoud, D. Rémond, M. Faure, D. Breuille, G. Williamson, E. Peré-Trepat, Z. Ramadan, L.-B. Fay, S. Kochhar. Simultaneous measurement of ${ }^{13} \mathrm{C}-$ and ${ }^{15} \mathrm{~N}$-isotopic enrichments of threonine by mass spectrometry. Rapid Commun. Mass Spectrom. 2009, 23, 1109.

[5] T. Preston, A.C. Small. Improved measurement of protein synthesis in human subjects using ${ }^{2} \mathrm{H}$-phenylalanine isotopomers and gas chromatography/mass spectrometry. Rapid Commun. Mass Spectrom. 2010, 24, 549.

[6] V. Sauvinet, L. Gabert, D. Qin, C. Louche-Pélissier, M. Laville, M. Désage. Validation of pentaacetylaldononitrile derivative for dual ${ }^{2} \mathrm{H}$ gas chromatography/mass spectrometry and ${ }^{13} \mathrm{C}$ gas chromatography/combustion/isotope ratio mass spectrometry analysis of glucose. Rapid Commun. Mass Spectrom. 2009, 23, 3855.

[7] J.-A. Nazare, A. de Rougemont, S. Normand, V. Sauvinet, M. Sothier, S. Vinoy, M. Désage, M. Laville. Effect of postprandial modulation of glucose availability: short- and long-term analysis. Br. J. Nutr. 2010, 103, 1461.

[8] A. Bergouignan, G. Trudel, C. Simon, A. Chopard, D.A. Schoeller, I. Momken, S.B. Votruba, M. Desage, G.C. Burdge, G. Gauquelin-Koch, S. Normand, S. Blanc. Physical inactivity differentially alters dietary oleate and palmitate trafficking. Diabetes 2009, 58, 367.

[9] L.S. Sidossis, A.R. Coggan, A. Gastaldelli, R.R. Wolfe. Pathway of free fatty acid oxidation in human subjects. Implications for tracer studies. J. Clin. Invest. 1995, 95, 278.

[10] L.S. Sidossis, A.R. Coggan, A. Gastaldelli, R.R. Wolfe. A new correction factor for use in tracer estimations of plasma fatty acid oxidation. Am. J. Physiol. 1995, 269, E649.

[11] S.B. Votruba, S.M. Zeddun, D.A. Schoeller. Validation of deuterium labeled fatty acids for the measurement of dietary fat oxidation: a method for measuring fat-oxidation in free-living subjects. Int. J. Obes. Relat. Metab. Disord. 2001, 25, 1240.

[12] S.J. Prosser, C.M. Scrimgeour. High-precision determination of ${ }^{2} \mathrm{H} /{ }^{1} \mathrm{H}$ in $\mathrm{H}_{2}$ and $\mathrm{H}_{2} \mathrm{O}$ by continuous-flow isotope ratio mass spectrometry. Anal. Chem. 1995, 67, 1992.

[13] D.C. McMillan, T. Preston, D.P. Taggart. Analysis of ${ }^{18} \mathrm{O}$ enrichment in biological fluids by continuous flow-isotope ratio mass spectrometry. Biomed. Environ. Mass Spectrom. 1989, 18, 543.

[14] C. Huber, M. Leuenberger. Fast high-precision on-line determination of hydrogen isotope ratios of water or ice by continuous-flow isotope ratio mass spectrometry. Rapid Commun. Mass Spectrom. 2003, 17, 1319.

[15] W.A. Brand, A.R. Tegtmeyer, A. Hilkert. Compound-specific isotope analysis: extending toward ${ }^{15} \mathrm{~N} /{ }^{14} \mathrm{~N}$ and ${ }^{18} \mathrm{O} /{ }^{16} \mathrm{O}$. Org. Geochem. 1994, 21, 585.

[16] G.D. Farquhar, B.K. Henry, J.M. Styles. A rapid on-line technique for determination of oxygen isotope composition of nitrogen-containing organic matter and water. Rapid Commun. Mass Spectrom. 1997, 11, 1554.

[17] J. Koziet. Isotope ratio mass spectrometric method for the on-line determination of oxygen-18 in organic matter. J. Mass Spectrom. 1997, 32, 103.

[18] S. Epstein, T. Mayeda. Variation of O 18 content of waters from natural sources. Geochim. Cosmochim. Acta 1953, 4, 213. 
[19] J.H. Rolston, J. Den Hartog, J.P. Butler. The deuterium isotope separation factor between hydrogen and liquid water. J. Phys. Chem. 1976, 80, 1064.

[20] J. Horita, A. Ueda, K. Mizukami, I. Takatori. Automatic $\mathrm{dD}$ and $\mathrm{d}^{18} \mathrm{O}$ analyses of multiwater samples using $\mathrm{H}_{2-}$ and $\mathrm{CO}_{2}$-water equilibration methods with a common equilibration set-up. Appl. Radiat. Isot. 1989, 40, 801.

[21] C. Bossu, B. Galusca, S. Normand, N. Germain, P. Collet, D. Frere, F. Lang, M. Laville, B. Estour. Energy expenditure adjusted for body composition differentiates constitutional thinness from both normal subjects and anorexia nervosa. Am. J. Physiol. Endocrinology And Metabolism 2007, 292, E132.

[22] D. Jacobi, A.-E. Perrin, N. Grosman, M.-F. Dore, S. Normand, J.-M. Oppert, C. Simon. Physical Activity-Related Energy Expenditure With the RT3 and TriTrac Accelerometers in Overweight Adults. Obesity 2007, 15, 950.

[23] M. Bonnefoy, M. Laville, R. Ecochard, J.-F. Jusot, S. Normand, S. Maillot, B. Lebreton, M. Jauffret. Effects of branched amino acids supplementation in malnourished elderly with catabolic status. J. Nutr. Health Aging 2010, 14, 579.

[24] T.B. Coplen, I.T. Harper. An improved technique for the ${ }^{2} \mathrm{H} /{ }^{1} \mathrm{H}$ analysis of urines from diabetic volunteers. Biol. Mass Spectrom. 1994, 23, 437.

[25] D.A. Schoeller, A.H. Luke. Rapid ${ }^{18} \mathrm{O}$ analysis of $\mathrm{CO}_{2}$ samples by continuous-flow isotope ratio mass spectrometry. J. Mass Spectrom. 1997, 32, 1332.

[26] W.A. Brand, T.B. Coplen, A.T. Aerts-Bijma, J.K. Böhlke, M. Gehre, H. Geilmann, M. Gröning, H.G. Jansen, H.A.J. Meijer, S.J. Mroczkowski, H. Qi, K. Soergel, H. StuartWilliams, S.M. Weise, R.A. Werner. Comprehensive inter-laboratory calibration of reference materials for delta ${ }^{18} \mathrm{O}$ versus VSMOW using various on-line high-temperature conversion techniques. Rapid Commun. Mass Spectrom. 2009, 23, 999.

[27] M. Richelle, C. Darimont, C. Piguet-Welsch, L.B. Fay. High-throughput simultaneous determination of plasma water deuterium and 18-oxygen enrichment using a hightemperature conversion elemental analyzer with isotope ratio mass spectrometry. Rapid Commun. Mass Spectrom. 2004, 18, 795.

[28] N. Ripoche, V. Ferchaud-Roucher, M. Krempf, P. Ritz. D and ${ }^{18} \mathrm{O}$ enrichment measurements in biological fluids in a continuous-flow elemental analyser with an isotope-ratio mass spectrometer using two configurations. J Mass Spectrom. 2006, 41, 1212.

[29] H. Schierbeek, R. Rieken, K.Y. Dorst, C. Penning, J.B. van Goudoever. Validation of deuterium and oxygen 18 in urine and saliva samples from children using on-line continuous-flow isotope ratio mass spectrometry. Rapid Commun. Mass Spectrom. 2009, 23,3549 .

[30] J. Horita. Hydrogen isotope analysis of natural waters using an $\mathrm{H}_{2}$-water equilibration method: A special implication to brines. Chemical Geology: Isotope Geoscience section 1988, $72,89$.

[31] A.L. Sessions. Isotope-ratio detection for gas chromatography. J. Sep. Sci. 2006, 29, 1946.

[32] J. Olsen, I. Seierstad, B. Vinther, S. Johnsen, J. Heinemeier. Memory effect in deuterium analysis by continuous flow isotope ratio measurement. Int. J. Mass Spectrom. 2006, 254, 44.

[33] J. Morrison, T. Brockwell, T. Merren, F. Fourel, A.M. Phillips. On-Line High-Precision Stable Hydrogen Isotopic Analyses on Nanoliter Water Samples. Anal. Chem. 2001, 73, 3570 .

[34] M. Gehre, H. Geilmann, J. Richter, R.A. Werner, W.A. Brand. Continuous flow ${ }^{2} \mathrm{H} /{ }^{1} \mathrm{H}$ and ${ }^{18} \mathrm{O} /{ }^{16} \mathrm{O}$ analysis of water samples with dual inlet precision. Rapid Commun. Mass Spectrom. 2004, 18, 2650.

[35] F.H. Lu. Online high-precision $\delta^{2} \mathrm{H}$ and $\delta^{18} \mathrm{O}$ analysis in water by pyrolysis. Rapid Commun. Mass Spectrom. 2009, 23, 3144. 
[36] J.M. Bland, D.G. Altman. Statistical methods for assessing agreement between two methods of clinical measurement. Lancet 1986, 1, 307.

[37] J.T. Brenna, T.N. Corso, H.J. Tobias, R.J. Caimi. High-precision continuous-flow isotope ratio mass spectrometry. Mass Spectrom. Rev. 1997, 16, 227.

[38] A.J. Midwood, B.A. McGaw. Recent developments in the analysis of light isotopes by continuous flow isotope ratio mass spectrometry. Anal. Commun. 1999, 36, 291.

[39] N. Pace, E. Rathburn. Studies on body composition. III. The body water and chemically combined nitrogen content in relation to fat content. J. Biol. Chem. 1945, 158, 685. 
Table 1. ${ }^{18} \mathrm{O}$ - and ${ }^{2} \mathrm{H}$ - enrichments measured either by $\mathrm{CF}$-equilibration or $\mathrm{CF}-\mathrm{HTC}$ in enriched water samples including reference waters from IAEA (SLAP2, GISP and VSMOW2) and in enriched urine samples. Data were normalized against calibration points supplied by Iso-analytical Limited (IA R053, IA R054 and IA R055). Results are presented as the mean (in bold) \pm standard deviation (SD, in italic). The injection conditions are described in the experimental section for each method (paragraphs "Continuous Flow Equilibration" and "Continuous Flow High Temperature Conversion"). Measurements were done in 3 batches of analyses performed on 3 different days using both techniques (Run1, Run 2 and Run 3). 


\begin{tabular}{|c|c|c|c|c|c|c|c|c|c|c|c|c|c|}
\hline & & \multicolumn{6}{|c|}{${ }^{18} \mathrm{O}$} & \multicolumn{6}{|c|}{${ }^{2} \mathrm{H}$} \\
\hline & & \multicolumn{3}{|c|}{ CF-Equilibration } & \multicolumn{3}{|c|}{ CF-HTC } & \multicolumn{3}{|c|}{ CF-Equilibration } & \multicolumn{3}{|c|}{ CF-HTC } \\
\hline & & Slope & Intercept & $\mathbf{R}^{2}$ & Slope & Intercept & $\mathbf{R}^{2}$ & Slope & Intercept & $\mathbf{R}^{2}$ & Slope & Intercept & $\mathbf{R}^{2}$ \\
\hline & Run 1 & 1.0009 & 0.5598 & 1.0000 & 0.9997 & 0.4017 & 1.0000 & 0.9991 & 2.1431 & 1.0000 & 0.9939 & 2.8098 & 1.0000 \\
\hline \multirow[t]{4}{*}{$\mathrm{H}_{2} \mathrm{O}$} & Run 2 & 1.0011 & 0.4322 & 1.0000 & 0.9982 & 0.5057 & 1.0000 & 0.9999 & -0.1234 & 0.9999 & 0.9958 & 2.0114 & 1.0000 \\
\hline & Run 3 & 1.0032 & 0.4498 & 1.0000 & 0.9981 & 0.3658 & 0.9999 & 0.9985 & 1.4399 & 0.9999 & 0.9931 & 2.9819 & 1.0000 \\
\hline & Mean & 1.0017 & 0.4806 & 1.0000 & 0.9987 & 0.4244 & 1.0000 & 0.9992 & 1.1532 & 0.9999 & 0.9943 & 2.6010 & 1.0000 \\
\hline & $S D$ & 0.0013 & 0.0692 & $1.3 E-05$ & 0.0009 & 0.0726 & $1.9 E-05$ & 0.0007 & 1.1601 & $8.8 E-06$ & 0.0014 & 0.5178 & $1.5 E-06$ \\
\hline
\end{tabular}

Table 2. Regression parameters calculated from expected delta values (X-axis, Table 3 ) and ${ }^{18} \mathrm{O}$ - and ${ }^{2} \mathrm{H}$ - enrichments from enriched waters measured either by $\mathrm{CF}$-equilibration or $\mathrm{CF}$ HTC (Y-axis, Table 1). Isotopic enrichments ranged from $-55.5 \delta \%$ to $+220.7 \delta \%$ for ${ }^{18} \mathrm{O}$ and from $-428 \delta \%$ o to $+1418 \delta \%$ o for ${ }^{2} \mathrm{H}$ relative to VSMOW. Results are presented as the mean (in bold) \pm standard deviation (SD, in italic) of the 3 batches of analyses (Run 1, Run 2 and Run 3). 


\begin{tabular}{|c|c|c|c|c|c|c|c|c|}
\hline \multicolumn{2}{|c|}{ Accuracy $(\delta \% \circ)$} & \multirow[b]{2}{*}{$\begin{array}{c}\text { Expected } \\
(\delta \% \circ)\end{array}$} & \multicolumn{3}{|c|}{ CF-Equilibration } & \multicolumn{3}{|c|}{ CF-HTC } \\
\hline & & & Run 1 & Run 2 & Run 3 & Run 1 & Run 2 & Run 3 \\
\hline \multirow{12}{*}{${ }^{18} \mathrm{O}$} & SLAP2 & -55.5 & -0.04 & -0.20 & -0.46 & -0.26 & -0.54 & -0.48 \\
\hline & GISP & -24.8 & -0.06 & -0.09 & -0.18 & 0.01 & 0.06 & 0.26 \\
\hline & $\mathrm{H} 2 \mathrm{O} 1$ & -8.2 & -0.57 & -0.49 & -0.45 & -0.49 & 0.02 & 0.09 \\
\hline & $\mathrm{H} 2 \mathrm{O} 2$ & -5.3 & -0.70 & -0.62 & -0.62 & -0.66 & -0.26 & -0.01 \\
\hline & VSMOW2 & 0.0 & 0.01 & 0.06 & 0.02 & -0.42 & -0.93 & -1.76 \\
\hline & $\mathrm{H} 2 \mathrm{O} 3$ & 1.0 & -0.69 & -0.56 & -0.52 & -0.32 & -0.36 & -0.29 \\
\hline & $\mathrm{H} 2 \mathrm{O} 4$ & 12.5 & -1.17 & -0.75 & -0.43 & -0.17 & -1.04 & -0.55 \\
\hline & $\mathrm{H} 2 \mathrm{O} 5$ & 27.9 & -1.08 & -0.69 & -0.76 & -0.54 & -0.85 & -0.48 \\
\hline & $\mathrm{H} 2 \mathrm{O} 6$ & 47.8 & -0.97 & -0.70 & -0.87 & -0.90 & -0.77 & -0.22 \\
\hline & $\mathrm{H} 2 \mathrm{O} 7$ & 101.8 & -1.01 & -0.72 & -0.59 & -0.52 & -0.63 & -0.14 \\
\hline & $\mathrm{H} 2 \mathrm{O} 8$ & 220.7 & -0.24 & $\begin{array}{l}-0.43 \\
-0.4 * \ldots\end{array}$ & $\begin{array}{l}-1.19 \\
-1.19\end{array}$ & -0.06 & 0.30 & 0.15 \\
\hline & Mean \pm SD & & \multicolumn{3}{|c|}{$-0.54 \pm 0.30$} & \multicolumn{3}{|c|}{$-0.39 \pm 0.34$} \\
\hline \multirow{12}{*}{${ }^{2} \mathrm{H}$} & SLAP2 & -428.0 & 0.32 & 5.52 & 1.22 & -7.07 & -4.10 & -8.04 \\
\hline & GISP & -189.5 & 2.27 & 1.41 & 1.93 & -2.44 & -1.08 & -2.74 \\
\hline & $\mathrm{H} 2 \mathrm{O} 1$ & -65.2 & -0.91 & -1.09 & 0.42 & -3.02 & -2.15 & -3.05 \\
\hline & $\mathrm{H} 2 \mathrm{O} 2$ & -23.9 & -2.17 & -2.97 & -6.93 & -3.21 & -2.72 & -3.16 \\
\hline & VSMOW2 & 0.0 & -0.77 & 3.04 & 2.19 & -1.18 & -1.46 & -1.73 \\
\hline & $\mathrm{H} 2 \mathrm{O} 3$ & 16.2 & -4.48 & -2.03 & -0.94 & -1.91 & -1.36 & -2.00 \\
\hline & $\mathrm{H} 2 \mathrm{O} 4$ & 58.0 & -8.51 & -1.36 & -8.46 & -4.37 & -3.95 & -4.08 \\
\hline & $\mathrm{H} 2 \mathrm{O} 5$ & 194.2 & -4.83 & -1.42 & -3.38 & -1.00 & -0.73 & -0.87 \\
\hline & $\mathrm{H} 2 \mathrm{O} 6$ & 471.7 & -2.15 & -0.96 & -0.32 & 1.49 & 1.57 & 1.88 \\
\hline & $\mathrm{H} 2 \mathrm{O} 7$ & 822.5 & -3.80 & -5.28 & -2.89 & -2.32 & -3.28 & -2.39 \\
\hline & $\mathrm{H} 2 \mathrm{O} 8$ & 1218.3 & 3.22 & 6.71 & 4.48 & 6.75 & 5.79 & 7.68 \\
\hline & Mean \pm SD & & \multicolumn{3}{|c|}{$-1.00 \pm 3.33$} & \multicolumn{3}{|c|}{$-1.52 \pm 3.39$} \\
\hline
\end{tabular}

Table 3. Accuracy (difference between the expected value and the measured value in \%o) of ${ }^{2} \mathrm{H}$ - and ${ }^{18} \mathrm{O}$ - measurements in water using either CF-Equilibration or CF-HTC. Accuracy results were calculated from data presented in Table 1 . Three batches of analyses were performed on 3 different days using both techniques (Run1, Run 2 and Run 3). 


\begin{tabular}{clcc}
\hline Correlation parameters & ${ }^{18} \mathrm{O}$ & ${ }^{2} \mathrm{H}$ \\
\hline \multirow{2}{*}{$\mathrm{H} 2 \mathrm{O}$} & Slope & 1.0030 & 1.0049 \\
& Intercept & 0.0558 & -1.4604 \\
& $\mathrm{R}$ & 1.0000 & 1.0000 \\
\multirow{4}{*}{ Urine } & Slope & 0.9993 & 0.9948 \\
& Intercept & 0.7228 & 8.4954 \\
& $\mathrm{R}$ & 1.0000 & 1.0000 \\
\hline
\end{tabular}

Table 4. Correlation between $\delta^{18} \mathrm{O}$ - and $\delta^{2} \mathrm{H}$ - measurements obtained from CF-Equilibration (Y-axis) and CF-HTC (X-axis) techniques. The correlation parameters were calculated from data presented in Table 1. The samples were enriched and non-enriched waters (including reference waters from IAEA, SLAP2, GISP and VSMOW2) or ${ }^{18} \mathrm{O}$ - and ${ }^{2} \mathrm{H}$ - enriched urines. All were measured in 3 batches of analyses performed on 3 different days using both techniques. Injection conditions are described in the experimental section. 

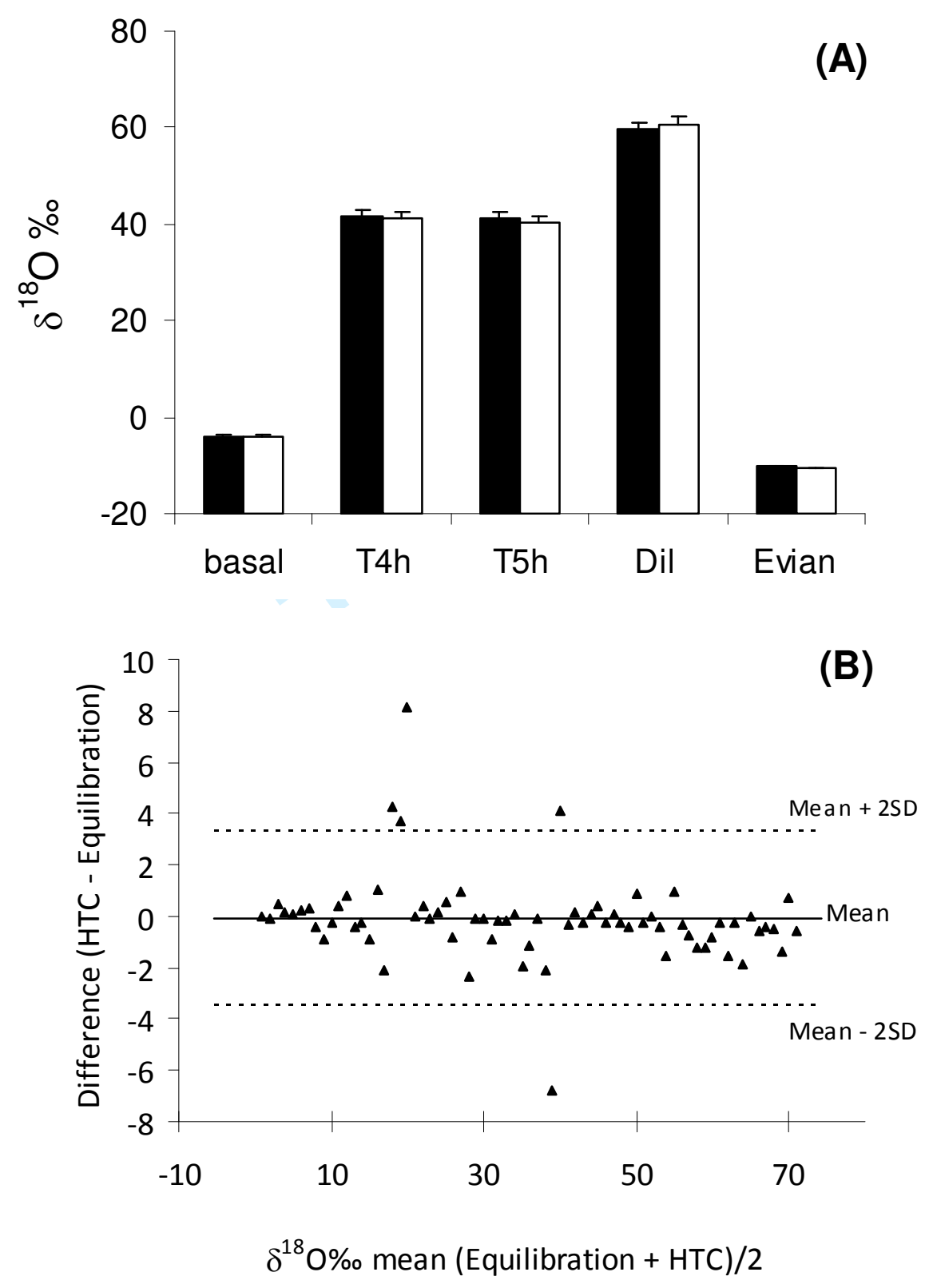

Figure 1. $\delta^{18} \mathrm{O} \%$ enrichments in urine (basal, T4h and T5h) after ingestion of $\mathrm{H}_{2}{ }^{18} \mathrm{O}\left(0.5 \mathrm{~g} . \mathrm{kg}^{-}\right.$ ${ }^{1}, 10 \%{ }^{18} \mathrm{O}$ ), and in the dilution of the ingested $\mathrm{H}_{2}{ }^{18} \mathrm{O}$ dose in Evian water (Dil.) (Fig.2(A)).

Data are presented as the mean values ( \pm sem) for samples of 14 subjects measured by continuous flow IRMS coupled to either an equilibration device ( $\square$ ) or a HTC device ( $\square$ ). A Bland and Altman test (Fig.2(B)) shows differences between results from both methods as a function of the average of results obtained with each method. This diagram shows a mean bias of $0.119 \%$ o between the two methods, with a confidence interval between -3.51 and $+3.27 \%$ o 

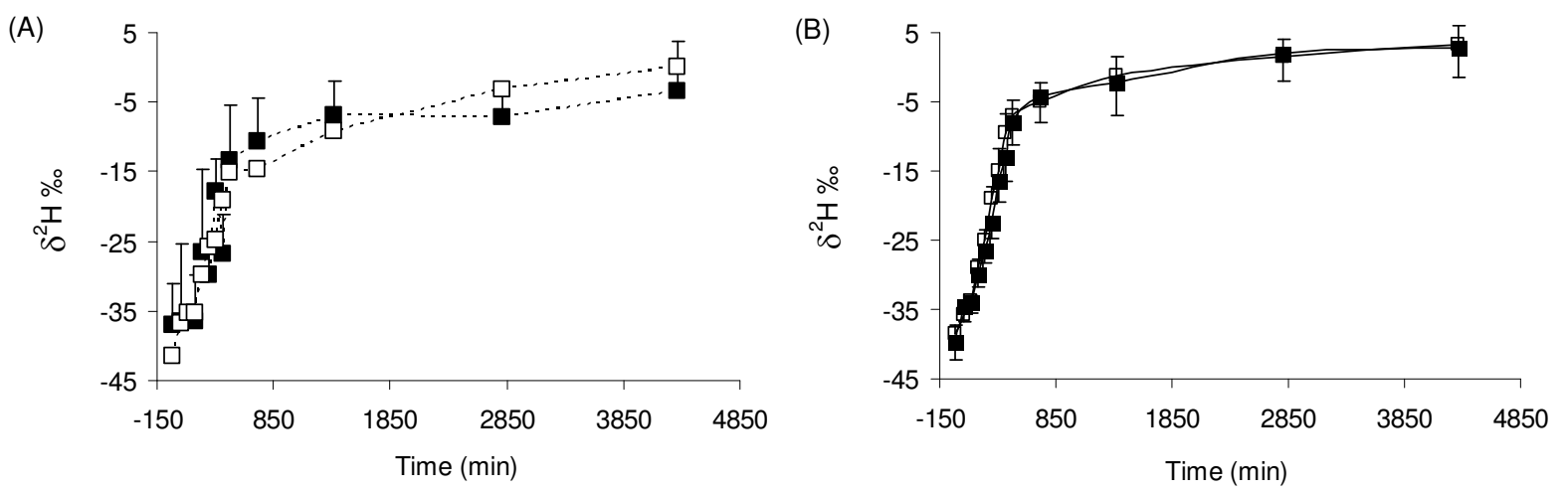

Figure 2. $\delta^{2} \mathrm{H} \%$ o evolution in urine until 3 days after ingestion of $\mathrm{d}_{31}$-palmitic acid (20mg.kg${ }^{1}$ ) measured by continuous flow IRMS coupled either to an equilibration device (ם) or a HTC device $(\square)$. Data are presented as the mean of injections $( \pm$ SD) for 1 subject $(\mathrm{A})$ and as the mean values $\left( \pm\right.$ sem) for 14 subjects (B). A mixed model showed no difference for the $\delta^{2} \mathrm{H} \%$ 。 measurement between the two methods used $(\mathrm{p}=0.513)$. 


\begin{tabular}{cccc} 
(A) Subject & Equilibration & HTC & $\neq$ \\
\hline 1 & 47.5 & 46.8 & 0.7 \\
2 & 48.4 & 48.7 & 0.3 \\
3 & 45.5 & 45.4 & 0.1 \\
4 & 46.1 & 45.1 & 1.0 \\
5 & 42.8 & 44.2 & 1.4 \\
6 & 44.7 & 46.6 & 1.9 \\
7 & 37.3 & 36.7 & 0.6 \\
8 & 38.0 & 40.1 & 2.1 \\
9 & 46.0 & 46.6 & 0.6 \\
10 & 44.9 & 46.1 & 1.2 \\
11 & 45.4 & 46.8 & 1.4 \\
12 & 44.6 & 44.7 & 0.1 \\
13 & 49.8 & 48.9 & 0.9 \\
14 & 51.1 & 53.3 & 2.2 \\
\hline
\end{tabular}

(B)

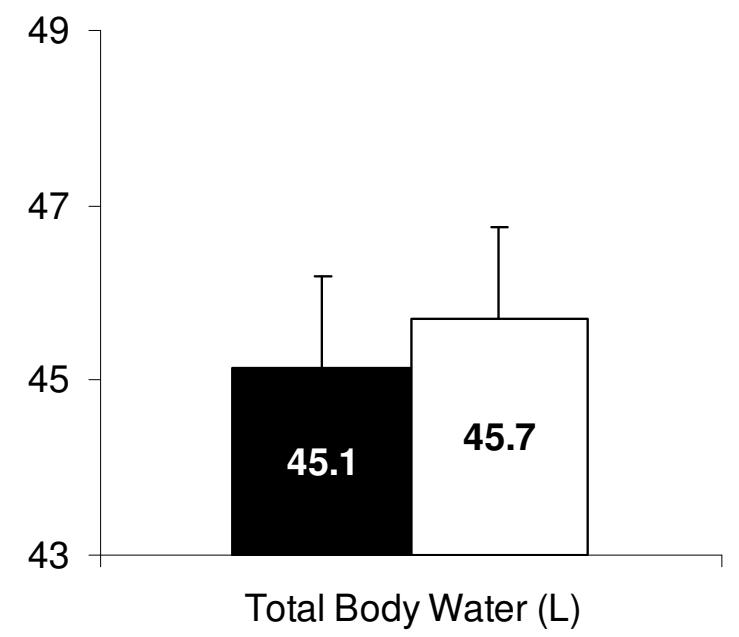

Figure 3. Total body water in L calculated from $\delta^{18} \mathrm{O} \%$ onrichments measured either with equilibration ( $\square$ ) or HTC ( $\square$ ) techniques, using equations (1) and (2) (See experimental section). Individual results and differences $(\neq)$ between values for the 14 subjects are presented (A) and the average \pm sem (B). No significant difference in volumes of Total Body Water depending on the analytical method was revealed (paired t-test, $\mathrm{p}=0.0869$ ). 

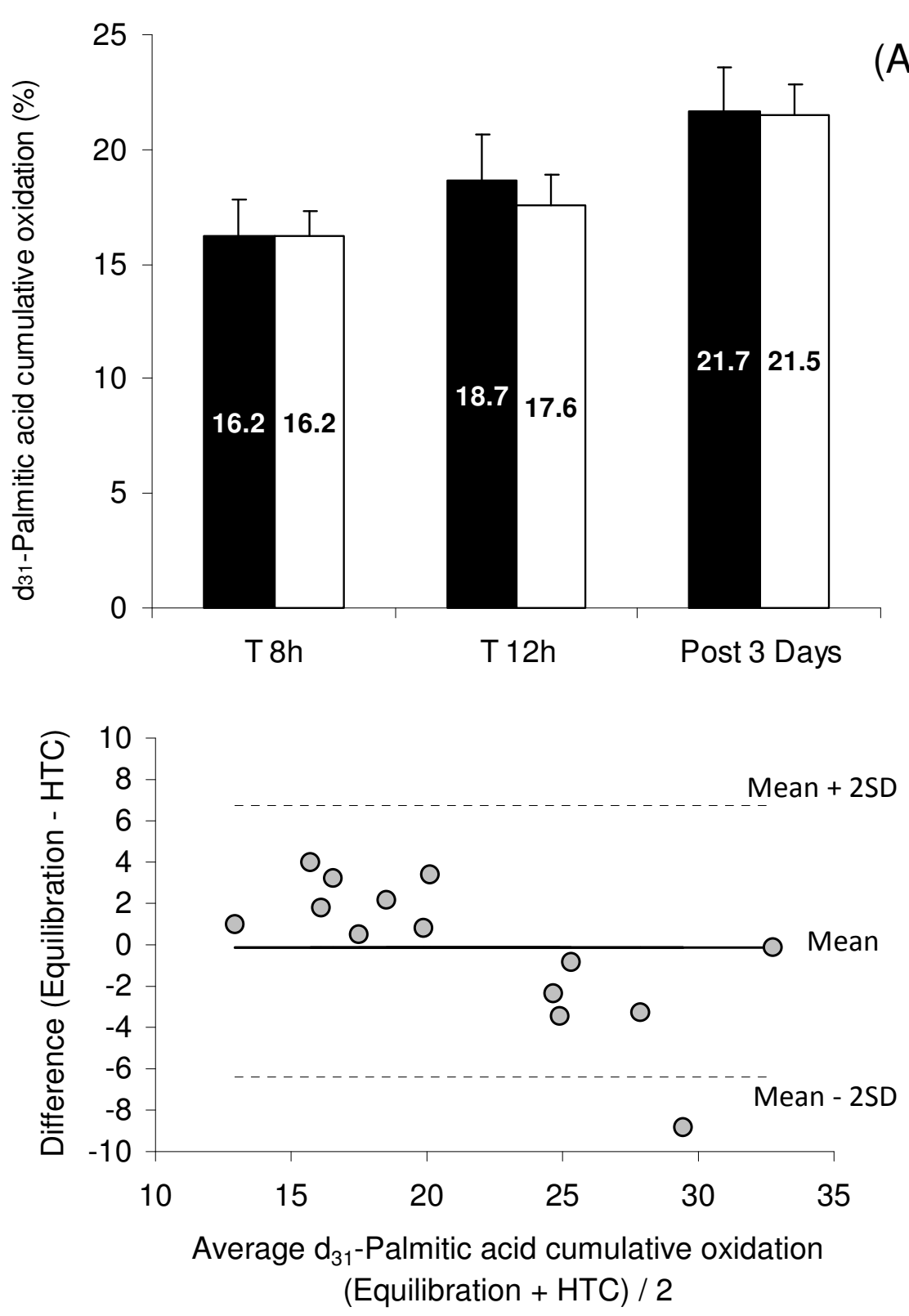

Figure 4. Cumulative recoveries expressed in $\%$ (mean \pm sem) of $\mathrm{d} 31$-palmitic acid until 3 days post-ingestion (Fig.4(A)), were calculated from $\delta^{2} \mathrm{H} \%$ o enrichment measurements and TBW obtained either from equilibration ( $\square$ ) or HTC ( $\square$ ) techniques, using equation (3) (See experimental section). Data are presented as the mean values ( \pm sem) obtained from the samples of 14 subjects. A paired t-test showed no significant difference for d31-palmitic acid recovery calculated either from equilibration data or HTC data, at $\mathrm{T} 8 \mathrm{~h}(\mathrm{p}=0.9715), \mathrm{T} 12 \mathrm{~h}$ $(\mathrm{p}=0.2616)$ and 3 days post-dose $(\mathrm{p}=0.8840)$. A Bland and Altman test (Fig.4(B)) shows differences between results from both methods as a function of the average of results obtained with each method. This diagram shows a mean bias of $-0.14 \%$ according the analytical methods used, with a confidence interval between -6.39 to $+6.75 \%$. 